\title{
CONE BEAM COMPUTED TOMOGRAPHY EVALUATION OF TWO OBTURATION TECHNIQUES AFTER PREPARATION WITH TWO NOVEL ROTARY SYSTEMS (IN VITRO STUDY)
}

\author{
Rodayna M. Ellakany ${ }^{l} B D S$, Mohamed M. Ibrahim²$P h D$, Nayera A. Mokhless ${ }^{3} P h D$
}

\begin{abstract} adaptation of the root filling to the canal walls to create a homogenous mass of filling.

OBJECTIVES: To compare the obturation quality of different obturation techniques in curved canals using two rotary systems by CBCT. MATERIALS AND METHODS: Forty mesial roots of mandibular first molars were selected, decoronated to $12 \mathrm{~mm}$ length and divided into two subgroups $\left(\mathrm{B}_{1}, \mathrm{~B}_{2}\right)$ were obturated using cold lateral compaction technique. Pre and post obturation CBCT images were used to assess the volume of voids in the filled canals. Data were analyzed using Kruskal-Wallis and Mann-Whitney tests. (13.41 \pm 9.11$)$, while subgroup B2 showed higher amount of voids with mean percentage (23.17 \pm 5.27$)$ than subgroups $\left(A_{1}\right.$ and $\left.A_{2}\right)$. At the middle volume of voids than lateral compaction subgroups.

CONCLUSIONS: Protaper Next group obturated with lateral compaction technique provided the least amount of voids followed by the two single cone subgroups, while Wave one group obturated with lateral compaction technique provided the highest amount of voids.

KEYWORDS: CBCT, Protaper Next files, Wave one files, AH plus, Lateral Compaction, single cone technique.

1- Bachelor of Dentistry, BDS, Faculty of Dentistry, Misr University for Science and Technology, $6^{\text {th }}$ of October city, Egypt.

2- Professor of Endodontics, Faculty of Dentistry, Alexandria University, Alexandria, Egypt.

3- Assistant Professor of Endodontics, Faculty of Dentistry, Alexandria University, Alexandria, Egypt.
\end{abstract}

INTRODUCTION: Three dimensional obturation is an essential factor for the success of root canal treatment which is achieved by the groups $(\mathrm{n}=20)$. Group I: instrumented with Protaper Next file system; Group II: instrumented with Wave One primary file, then they were subdivided into subgroups $\left(A_{1}, A_{2}\right.$ and $\left.B_{1}, B_{2}\right)$ according to the obturation technique used . Subgroups $\left(A_{1}, A_{2}\right)$ were obturated with single cone technique while

RESULTS: Subgroup B1 showed the least amount of voids with percentage (14.82\%), while subgroup B2showed the highest amount of voids with percentage (40.16\%) when compared to the other subgroups. At the coronal level, subgroup B1 showed less volume of voids with mean percentage third, there was no significant difference between the four subgroups. Apically, single cone subgroups $\left(\mathrm{A}_{1}\right.$ and $\left.\mathrm{A}_{2}\right)$ produced significantly less

\section{INTRODUCTION}

The most important factors for a successful root canal treatment are biomechanical instrumentation of the root canal for disinfection and dissolution of organic matter to eliminate bacterial pathogens and the three-dimensional obturation of this space (1) for impeding the reinfection and hampering the flow of microorganisms and toxins to the peri-apical tissue (2-4).

Several techniques have been proposed to accomplish good adaptability of the root canal filling to the canal space including the cold lateral compaction which is considered the gold standard and the most common technique and the use of single-cone gutta-percha matching the taper and the diameter of the canals prepared with engine-driven nickeltitanium (NiTi) instruments (5).

Recently a new concept for NiTi files has been introduced with different working motions that finish root canal shaping with only a single file. One of these single-file systems is Wave One (WO) (DENTSPLY Tulsa Dental Specialties,Tulsa,OK) which is used in a reciprocating motion and is made of a special NiTi alloy (M-Wire) to increase flexibility and improve cyclic fatigue of the instrument (6-8). The primary WaveOne gutta-percha cones have a taper of 0.08 over the first $3 \mathrm{~mL}$ that reduce to $4.3 \%$ and $5.5 \%$, respectively (9).

Another novel NiTi file system is the ProTaper Next (PN) (Dentsply Maille fer, Ballaigues, Switzerland); it has an offset design , progressive and regressive percentage tapers on a single file and is made from M-Wire technology having various percentage tapers functions to decrease the screw effect and dangerous taper lock by minimizing the contact between a file and dentin(10).In the apical portion, Protaper Next instruments $(\mathrm{X} 1, \mathrm{X} 2$, and $\mathrm{X} 3)$ have less taper $(0.04,0.06$, and 0.07, respectively) than ProTaper Universal (PU) finishing files (F1, F2, and F3 and 0.07, 0.08, and 0.09, respectively)(11,12). The Pro-Taper Next X2 gutta percha cones have a taper of 0.06 at the first 3 mmof apical tip, and the other parts of the cone have both increasing and decreasing percentage tapers (13).

Previous studies in this field had limitations including measuring and calculating the percentage of surface areas of filling material and voids by analysis of sectioned roots and analysis of digital imaging software (14-17). These calculations might not be accurate because some filling material might be lost in the process of sectioning the teeth. Although the use of water cooling smearing of filling on the sectioned surface might also occur which may give inaccurate measurements of small voids area (18). Moreover these methods allow two dimensional views only of sections.

Cone beam computed tomography (CBCT) had been used in the present study to allow 3D reconstruction and visualization of external and internal anatomy of teeth (18) as it is considered a noninvasive method aiming to overcome limitations of previous methods. 
The aim of the present in vitro study was to compare different obturation techniques (single cone and cold lateral compaction) in curved canals prepared with two NiTi systems (Wave One and Protaper Next) in terms of the percentage of volume of voids and gaps in gutta- percha filled canals using cone beam computed tomography (CBCT).

\section{MATERIALS AND METHODS}

Forty mesial canals of mandibular first molar teeth with fully developed root apices were used in this study. Teeth were thoroughly cleaned from any soft tissue or calculus deposition using curettes.

Teeth were selected such that the mesial root curvature angle was equal or less than $20^{\circ}$ according to Schneider technique (19).

Access opening was performed by using high speed round and endo $-Z$ burs. A size \# $10 \mathrm{k}$-file was inserted through the canal $1 \mathrm{~mm}$ beyond the apical foramen to establish apical patency, and then the working length was determined.

The teeth were then divided into two groups $(n=20)$ according to instrumentation technique as follows:

\section{Group I:}

Instrumentation was done using Protaper Next with sequence PN (X1, X2) in brushing motion with rotational speed of 300 rpm and torque 2.0-5.2 using (X-Smart Plus electric motor), The ProTaper Next X1 (17/.04) instrument was introduced into the root canal and slid down the glide path up to the working length, and then it was pulled back to approximately 2-3 mm shorter than the working length, followed by a deliberate back stroke outward brushing motion away from any external root concavities. Finally, the file was taken to full working length apically, then an outward brushing (coronally) was performed This touch-and-brush sequence was repeated up to three or four times according to the manufacturer's recommendations. The ProTaper Next X2 instrument (25/.06) was introduced to the full working length using the same protocol discussed above.

\section{Group II:}

The canals were irrigated with $3 \mathrm{ml}$ of $2.5 \% \mathrm{NaOCl}$ using a 27 gauge needle. Wave One primary file was introduced into the canal, activated by X-Smart Plus electric motor and applied in reciprocating motion (according to the pre-saved program on the motor) in and out movement without pressure. Shaping procedure was performed until the file met resistance or reached the full working length. After three pecking motions, the instrument was removed from the canal, cleaned with sterile gauze and the canals were irrigated with $3 \mathrm{ml}$ of $2.5 \%$ $\mathrm{NaOCl}$ using a 27 gauge needle. This procedure was repeated until the instrument reached the original working length.

All specimens were scanned using Cone beam computed tomography (J.Morita R100 cone beam 3D imaging system) to scan the specimens at two stages (before obturation and after obturation of the root canals). The scan was done with a field of view (FOV) of $100 \mathrm{~mm} \times \mathrm{H} 80 \mathrm{~mm}$. The volumes of interest were then reconstructed with $0.260 \mathrm{~mm}$ isometric voxel size. The tube voltage was $90 \mathrm{kVp}$ and $8 \mathrm{~mA}$ and the exposure time was 9.4 seconds.

\section{Obturation}

After CBCT imaging, each group was subdivided into two subgroups according to obturation technique used:

Subgroup A1: single cone technique with Protaper Next matching single gutta percha cones corresponding to files (X2)
Subgroup A2: single cone technique with Wave one matching single gutta percha cones corresponding to primary file.

Subgroup B1: Lateral compaction technique with standardized gutta percha cones.

Subgroup B2: Lateral compaction technique with $0.2 \%$ standardized gutta percha cones.

AH-plus was used as sealer for all groups and mixed according to manufacturer's instructions.

For subgroups A1 and A2: small amounts of sealer were applied to the canal by using a K-file \#size 25 in a counterclockwise rotation. Then the single cone was coated with sealer and inserted inside the canal to the full working length.

For subgroups B1 and B2: master gutta percha cone size 25 (2\% taper) was selected and inserted into the canal, tug back was ensured, the canals were filled using lateral compaction technique by inserting spreader size \#25 coated with sealer $1 \mathrm{~mm}$ shorter than the working length next to the master cone and the accessory gutta-percha cones were placed in the space provided by the spreader. This process was repeated until the spreader did not penetrate more than 1-2 $\mathrm{mm}$ from the canal orifice.

After completion of obturation procedures, a heated plugger was used to remove the excess gutta-percha with no further vertical compaction.

The teeth were kept at $37^{\circ} \mathrm{C}$ with $100 \%$ humidity for 7 days to allow the sealer to set.

\section{Evaluation of the quality of root canal filling}

Before and after obturation, the canal of each specimen was traced and total volume was measured (as showed in Figure 1). The voids and gaps were determined by subtraction of the total volume of obturated canal from the unobturated canal then the volumes of those gaps were calculated. $\mathrm{V}_{\text {of voids }}=\mathrm{V}_{\text {pre }}-\mathrm{V}_{\text {post }}$

The percentage of volume of voids and gaps was analyzed separately for the apical, middle and coronal thirds of roots at intervals of $(3,6$, and $9 \mathrm{~mm}$, respectively).

\section{STATISTICAL ANALYSIS}

Data were collected, revised, coded and fed to statistical software IBM SPSS version 20. The given graphs were constructed using Microsoft excel software.

All statistical analysis were done using two tailed tests and alpha error of 0.05 . P value less than or equal to 0.05 was considered to be statistically significant and the results were analyzed using Independent sample T-test, Mann Whitney and Kruskal Wallis tests.

\section{RESULTS}

Regarding the volume of voids; all experimental groups showed voids within the root canal fillings. Although no significant difference was found between subgroup B1 and subgroups (A1 and A2), subgroup B1 showed less amount of voids with mean percentage (14.82\%) when compared to subgroups (A1 and A2) with mean percentage (24.59\%and $26.68 \%$ ), respectively. Subgroup B2 showed statistically significant higher amount of voids with mean percentage of $(40.16 \%)$ compared to all other groups. (As shown in table 1 and Fig. 2)

Regarding the volume of voids at apical, middle and coronal thirds $(3,6,9 \mathrm{~mm}$, respectively) from the apex; at the coronal third subgroup B1 showed the least amount of voids with a mean percentage $(13.41 \pm 9.11)$ with no 
significant difference with subgroup A1 with a mean percentage $(16.47 \pm 6.06)$ at $(p=0.388)$, while subgroup B2 had significantly higher percentage of voids with mean percentage $(23.17 \pm 5.27)$ than subgroup A2 with mean percentage $(16.80 \pm 6.54)$ at $(\mathrm{p}=0.027)$. At the middle third there was no significant difference between the four subgroups as the mean percentage for subgroup A1 was (33.36 \pm 5.26$)$, subgroup B1 was (31.96 \pm 7.73$)$, subgroup A2 was (35.38 \pm 6.63$)$ and subgroup B2 was (33.77 \pm 2.90$)$. Apically, the single cone technique subgroups showed significantly lower volume of voids than lateral compaction subgroups. For subgroups (A1 and B1) the mean percentages of voids were $(50.17 \pm 4.20)$ and $(54.63 \pm 5.57)$, respectively ( $p$ $=0.050)$, while for subgroups (A2and B2) the mean percentage were $(43.06 \pm 3.39)$ and $(47.82 \pm 5.58)$, respectively $(\mathrm{p}=0.033)$ (As shown in table 2).

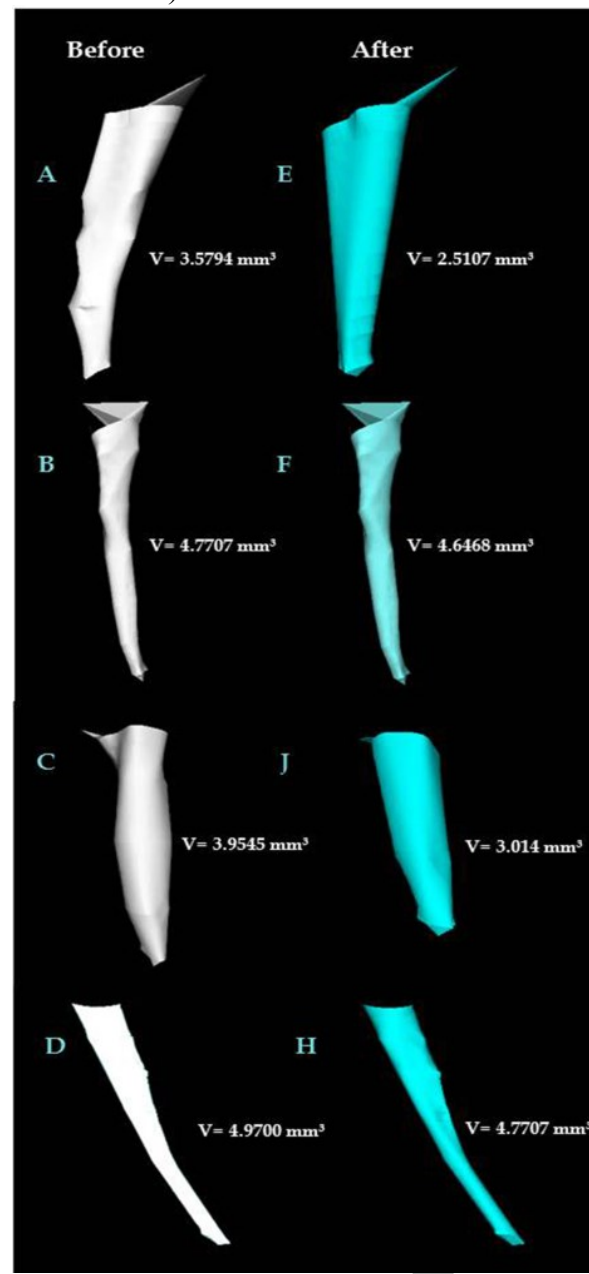

Figure 1: Comparison between the volumes of the canals before and after obturation for each sub group of the two groups

\section{DISCUSSION}

After proper chemomechanical debridement of the root canal system, subsequent 3-dimensional (3D) obturation of the canal space to full working length is another crucial treatment step that has an impact on the success of treatment outcome (20,21).

Several techniques combining gutta-percha and sealers have been proposed to ensure void-free obturation of the debrided root canal space and to accomplish good adaptability of the root canal filling material (22).

The present study evaluated the obturation quality of two techniques (single cone obturation technique and lateral compaction technique) in terms of the percentage of voids using two NiTi systems of two different motions techniques: reciprocating technique using Wave One single file system and continuous rotation technique using Protaper Next file system. Evaluation of the obturation quality of their matching single cones according to the effect of the finishing file taper on the prepared canal was done.

The current study showed no significant difference between the two variable taper single cones of the rotary systems, Shafer et al (9) also found no significant difference between variable taper cones when using (Protaper Universal, Wave one and Reciproc) file systems.

Our study showed that the type of instrument and its taper had an effect on the quality of obturation where the Protaper Next group exhibited better results than Wave One group. This was in agreement with Caper et al (13) who found higher percentage of gutta percha in canals prepared with ProtaperNext file than canals prepared with Wave One file.This could be attributed to Protaper Next file design and its swaggering action which might increase the volume of filling material inside the canal enhancing the quality of obturation .On the other hand, Shafer et al (23) found that the type of instrument and its taper used had no influence on the quality of obturation as he found no significant difference in percentage of gutta percha after using both variable and constant taper finishing files.

Mesial roots of mandibular first molars were selected for our study, with standardization of the angle of curvature to be of moderate curvature $\left(10^{\circ}-20^{\circ}\right)$ according to Schneider's classification(19). Caper et al (13) used mesial curved roots of mandibular molar as the preparation of a curved canal may cause canal transportation, and subsequently result in a root canal shape that does not match the corresponding single gutta percha cones. This could result in voids on the outer wall of the curve. However, Farea et al (24) and Zogheib et al (21) used straight round teeth in their study to minimize anatomical variation and allow standardization. Gordon et al (22) stated that the use of single cone relied on the original geometry of the canal so the use of the matched cones would commonly be suitable for the cases of mesial and distal roots of maxillary and mandibular molars of small diameters, while oval-shaped and root canals with larger diameters required excessive preparation with thick and more tapered instruments to fit the cones to the root canal.

After instrumentation and prior to obturation of the specimens, the teeth were scanned for estimating the volume of the empty spaces of the canals using cone beam computed tomography. The J. Morita R100 cone beam 3D imaging system was used due to its high resolution $(125 \mu \mathrm{m}$ voxel), as described by the manufacturer. The measurement of pre-obturation volumes of the canals allowed the precise estimation of volume of voids of specimens. This regimen was carried out by Naseri et al (25) who measured the pre and post obturation volumes for estimation of the volume of voids in the canals.

The only limitation of cone beam computed tomography (CBCT) method is that it couldn't distinguish between sealer and gutta percha. This was in accordance with Asheibi et al (26). On the other hand, Yigit et al (27) found the same limitation when using Micro cone beam computed tomography.

In the present study, the results showed that there was no significant difference between subgroup B1(Protaper Next group obturated with lateral compacted standardized gutta percha cones) and subgroups A1\&A2 (obturated with Protaper 
Next matching single cone and Wave One single cone, respectively), although subgroup B1 exhibited less percentage of voids than those two subgroups. This was in conjunction with Hammad et al (28), AlHadlaq et al (29), Shafer et al and (9)Shafer et al (23) who found that lateral compaction technique produced higher percentage of gutta percha when compared with single cone technique with no significant difference between them.

Moreover, we found that there was no significant difference between the single cone subgroups (A1and A2), although Protaper Next single cone subgroup exhibited less volume of voids than Wave One single cone subgroup .This was in accordance with Caper et al (13) who stated that matched cones of ProTaper Next files resulted in higher percentage of gutta percha than Wave One group and he found no significant differences between the different single cone groups with regard to percentage of voids at all levels.

Significantly greater percentage of voids was found in subgroup B2 (oburated with standardized gutta percha cones and prepared with Wave One primary one) than subgroups (A1 and A2).In contrast to our findings, studies made by Romania et al (30), ALHadlaq et al (29) and Shafer et al (23)found that single cone technique produced lower percentage of gutta percha and higher percentage of voids than lateral compaction technique.

On comparing the four subgroups at three different levels. At coronal level, greatest amount of voids was found in subgroup B2, while subgroup B1 showed the least volume of voids with no significant difference with subgroups (A1 and A2) which had approximately equal values. These findings were in agreement with Monticelli et al (31) and Shafer et al (23) who stated that lateral compaction technique produced less volume of voids at (coronal level) than single cone technique. At the middle level, there was no significant difference between the four subgroups (A1,A2,B1,B2).At the apical third, single cone technique subgroups (A1 and A2) produced significantly less volume of voids than lateral compaction subgroups (B1and B2). These findings were in agreement with studies carried by Hammad et al (28), Tasdemir et al (32) and Nica et al (33) who found that single cone technique was able to fill the apical part effectively as lateral compaction technique. This could be attributed to the large taper of single matching cone corresponding to the last finishing file. In contrast with these findings, Romania et al (30),Marciano et al (34)and Shafer et al(9)found no significant difference between single cone technique and lateral compaction technique at any level.

\section{CONCLUSIONS}

It was concluded from this study that:

1. None of the filling materials was able to provide a complete hermetic seal, where all subgroups showed voids.

2. Protaper Next group provided the best results at coronal and middle thirds compared to Wave One group when used with lateral compaction technique.

3. Single-cone obturation technique was able to fill the apical part effectively when compared to traditional lateral compaction technique.

\section{CONFLICT OF INTEREST}

The authors declare that they have no conflicts of interest.

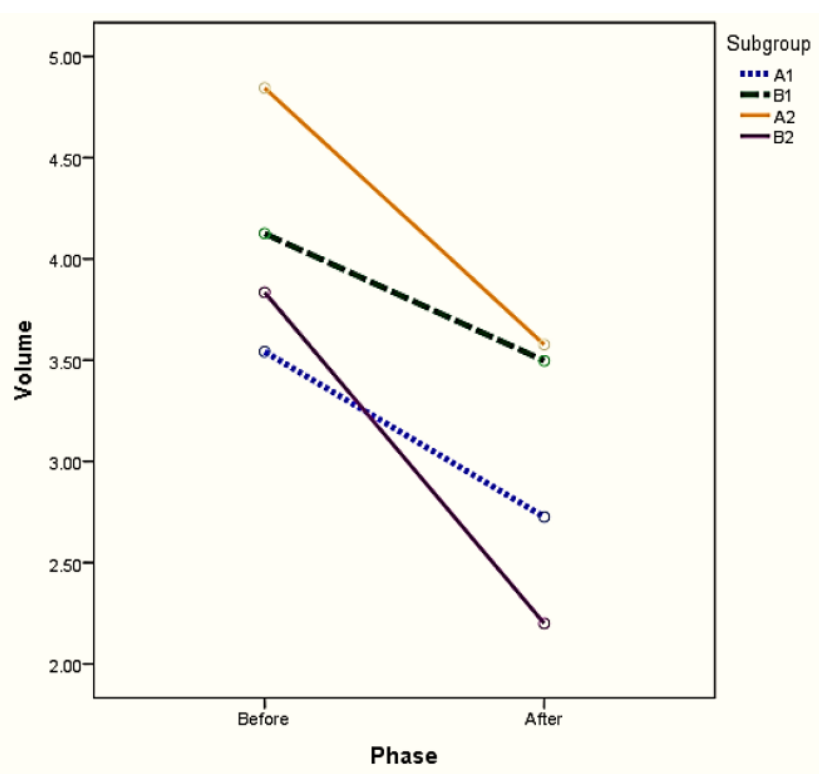

Figure 2: Samples A, B, C, D showed the volumes of the canals before obturation for subgroups $\left(A_{1}, B_{1}, A_{2}, B_{2}\right)$, respectively. Samples E, F, J, H showed the volumes of the canals after obturation for samples (A, B, C, D), respectively.

\section{REFERENCES}

1. Von Fraunhofer JA, Fagundes DK, McDonald NJ, Dumsha TC. The effect of root canal preparation on microleakage within endodontically treated teeth: an in vitro study. Int Endod J 2000; 33: 355-60.

2. Whitworth J. Methods of filling root canals: principles and practices. Endod Topics 2005; 12: 2-24.

3. Mollander A, Reit C, Dahlén G, Kvist T. Microbiological status of root-filled teeth with apical periodontitis. Int Endod J 1998; 31: 1-7.

4. Schilder H. Filling root canals in three dimensions. Dent Clin North Am 1967; 11: 723-44.

5. Zmener O, Pameijer CH, Macri E. Evaluation of the apical seal in root canals prepared with a new rotary system and obturated with a methacrylate based endodontic sealer: an in vitro study. J Endod 2005; 31 : 392-5

6. Wan J, Rasimick BJ, Musikant BL, Deutsch AS. A comparison of cyclic fatigue resistance in reciprocating and rotary nickel-titanium instruments. Aust Endod J 2011; 37: 122-7.

7. Celik D, Tasdemir T, Er K. Comparative study of 6 rotary nickel-titanium systems and hand instrumentation for root canal preparation in severely curved root canals of extracted teeth. J Endod 2013;39:278-82.

8. Marzouk AM, Ghoneim AG. Computed tomographic evaluation of canal shape instrumented by different kinematics rotary nickel-titanium systems. J Endod 2013; 39:906-9.

9. Schafer E, Koster M, Burklein S. Percentage of guttapercha filled areas in canals instrumented with nickeltitanium systems and obturated with matching single cones. J Endod 2013;39:924-8.

10. Versiani MA, Leoni GB, Steier L, De-Deus G, Tassani $\mathrm{S}$, Pécora JD, et al. Micro-computed tomography study of oval shaped canals prepared with the Selfadjusting File, Reciproc, WaveOne, and Pro-Taper Universal Systems. J Endod 2013;39:1060-6. 
Table 1: Percentage of voids between the four studied subgroups.

\begin{tabular}{|c|c|c|c|c|c|c|c|c|c|}
\hline \multirow{2}{*}{ Group } & \multirow{2}{*}{ Subgroup } & \multicolumn{3}{|c|}{ Volume of voids } & \multirow{2}{*}{${ }^{\mathbf{U}} \mathbf{P}$} & \multicolumn{3}{|c|}{ Volume \% of voids } & \multirow{2}{*}{${ }^{\mathbf{U}} \mathbf{P}$} \\
\hline & & Mean & SD & Median & & Mean & SD & Median & \\
\hline \multirow{2}{*}{$\begin{array}{l}\text { Protaper } \\
\text { Next }\end{array}$} & A1 & 00.82 & 00.67 & 0.70 & \multirow{2}{*}{$\begin{array}{c}0.53 \\
(0.597)\end{array}$} & 24.59 & 18.81 & 19.90 & \multirow{2}{*}{$\begin{array}{c}1.2 \\
(0.226)\end{array}$} \\
\hline & B1 & 00.63 & 00.54 & 0.43 & & 14.82 & 9.58 & 12.76 & \\
\hline \multirow{2}{*}{ Wave One } & $\mathrm{A} 2$ & 10.27 & 00.93 & 1.02 & \multirow{2}{*}{$\begin{array}{c}0.45 \\
(0.650)\end{array}$} & 26.68 & 18.62 & 22.69 & \multirow{2}{*}{$\begin{array}{c}2.3 \\
(0.049)^{*}\end{array}$} \\
\hline & B2 & 10.63 & 10.12 & 1.51 & & 40.16 & 18.83 & $40.81^{\mathrm{d}}$ & \\
\hline \multicolumn{2}{|c|}{$\mathbf{P}+$} & \multicolumn{3}{|c|}{$6.5(0.088)$} & & \multicolumn{3}{|c|}{$8.8(0.033) *$} & \\
\hline
\end{tabular}

U: Mann-Whitney d: significantly different group

$\mathrm{P}+$ : Kruskal-Wallis test

Table 2: Percentage of voids at coronal, middle and apical thirds for the four subgroups.

\begin{tabular}{|c|c|c|c|c|c|c|c|c|c|c|}
\hline \multirow{3}{*}{ Section } & A & & & & \multirow{3}{*}{$\mathbf{t}(\mathrm{P})$} & A & & & & \multirow{3}{*}{$\mathbf{t}(\mathbf{P})$} \\
\hline & \multicolumn{4}{|c|}{ Protaper Next } & & \multicolumn{4}{|c|}{ Wave One } & \\
\hline & Mean & SD & Mean & SD & & Mean & SD & Mean & SD & \\
\hline Coronal voids \% & 16.47 & 6.06 & 13.41 & 9.11 & $0.88(0.388)$ & 16.80 & 6.54 & 23.17 & 5.27 & $3.4(0.027)^{*}$ \\
\hline Middle voids \% & 33.36 & 5.26 & 31.96 & 7.73 & $0.47(0.643)$ & 35.38 & 6.63 & 33.77 & & $0.71(0.489)$ \\
\hline Apical voids \% & 50.17 & 4.20 & 54.63 & 50.57 & $2.0(0.050)^{*}$ & 43.06 & 3.39 & 47.82 & 5.5 & $2.3(0.033)^{*}$ \\
\hline
\end{tabular}

t: independent t-test

$* \mathrm{P}<0.05$ (significant)

11. Ruddle CJ. The ProTaper endodontic system: geometries, features, and guidelines for use. Dent Today 2001; 20: 60-7.

12. Ruddle CJ, Machtou P, West JD. The shaping movement: fifth-generation technology. Dent Today 2013; 32: 96-9.

13. Capar ID, Ertas H, Ok E, Arslan H, Ertas ET. Comparative study of different novel nickel-titanium rotary systems for root canal preparation in severely curved root canals. J Endod 2014;40:852-6.

14. Elayouti A, Achleithner C, Lost C, Weiger R. Homogeneity and adaptation of a new gutta-percha paste to root canal walls. J Endod 2005; 31: 687-90.

15. Epley SR, Fleischman J, Hartwell G, Cicalese C. Completeness of root canal obturations: Epiphany techniques versus gutta-percha techniques. J Endod 2006; 32: 541-4.

16. James BL, Brown CE, Legan JJ, Moore BK, Vail MM. An in vitro evaluation of the contents of root canals obturated with guttapercha and AH-26 sealer or Resilon and Epiphany sealer. J Endod 2007; 33: 135963.

17. Gulsahi K, Cehreli ZC, Onay EO, Tasman-Dagli F, Ungor M. Comparison of the area of resin-based sealer and voids in roots obturated with Resilon and guttapercha. J Endod 2007; 33: 1338-41.

18. Patel S, Horner K. The use of cone beam computed tomography in endodontics. Int Endod J 2009; 42: 755-6.

19. Ingle JI, Bakland LK. Obturation of the radicular space. In: Ingle JI, Bakland LK (eds). Endodontics. $4^{\text {th }}$ ed. Malvern, PA: Williams \& Wilkins, 1994. 598-614.
20. Schaeffer MA, White RR, Walton RE. Determining the optimal obturation length: ameta-analysis of literature. J Endod 2005;31:271-4.

21. Zogheib C, Naaman A, Medioni E, Bourbouze G, Chirani RA. The quality of Thermafil obturations with different final apical tapers: a three-dimensional microcomputed tomographic comparative study. J Contemp Dent Pract 2012;13:322-6.

22. Gordon MP, Love RM, Chandler NP. An evaluation of.06 tapered gutta-percha cones for filling of 06 taper prepared curved root canals. Int Endod J 2005;38:8796.

23. Schäfer E, Schrenker C, Zupanc J, Bürklein S. Percentage of Gutta-percha Filled Areas in Canals Obturated with Cross-linked Gutta-percha Corecarrier Systems, Single-Cone and Lateral Compaction Technique. J Endod 2016; 42: 294-8.

24. FareaM, RaniA, HuseinA,Masudis, PameijerCH. Evaluation of Gutta-Percha-Filled Areas in Root Canals after Filling by TwoDifferent Obturation Techniques. Aust J Basic ApplSci 2011; 5: 631-6.

25. Naseri M, Kangarlou A, Khavid A, Goodini M. Evaluation of the quality of four root canal obturation techniques using micro-computed tomography. Iran Endod J 2013; 8: 89-93.

26. Asheibi F, Qualtrough AJE, Mellor A, Withers PJ, Lowe T. Micro-CT Evaluation of Voids in the Filling Material of Single-Rooted Teeth Obturated with Different Techniques. J Res Pract Dent 2014; 2014: 110.

27. Yigit D, Yilmaz A, Sendur G, Aslan O, Abbot P. Efficacy of reciprocating and rotary systems for 
removing root filling material: A micro-computed tomography study. Scanning 2014; 36: 576-81.

28. Hammad M, Qualtrough A, Silikas N. Evaluation of root canal obturation: a three dimensional in vitro study. J Endod 2009; 35: 541-4.

29. Al-Hadlaq SM, Al-Jamhan A, Alsaeed T. Comparison of the single cone and lateralcompaction techniques in sealing 0.04 taper root canal preparations. Gen Dent 2010; 58: e219-22.

30. Romania C, Beltes P, Boutsioukis C, Dandakis C. Exvivo area-metric analysis of root canal obturation using gutta-percha cones of different taper. Int Endod J 2009;42:491-8.

31. Monticelli F, Sword J, Martin RL, Schuster GS, Weller RN, Ferrari M, et al. Sealing properties of two contemporary single-cone obturation systems. Int Endod J 2007; 40: 374-85.

32. Taşdemir T, Er K, Yildirim T, Buruk K, Celik D, Cora $\mathrm{S}$, et al. Comparison of the sealing ability of three fillingtechniques in canals shaped with two different rotary systems: a bacterial leakage study. Oral Surg Oral Med Oral Pathol Oral Radiol Endod 2009; 108: e129-34.

33. Nica LM, Didilescu A, Rusu D, Bacila A, Stratul SI. Photomicrographic evaluation of the apical sealing capacity of three types of gutta-percha master cones: an in vitro study. Odontology 2012; 100: 54-60.

34. Marciano MA, Ordinola-Zapata R, Cunha TV, Duarte MA, Cavenago BC, Garcia RB, et al. Analysis of four gutta-percha techniques used to fill mesial root canals of mandibular molars. Int Endod J 2011;44:321-9. 